\title{
O INSTITUTO DOS ESPONSAIS NA HISTÓRIA, NO DIREITO COMPARADO E NO DIREITO BRASILEIRO
}

\author{
Carlos Silveira Noronha ${ }^{1}$
}

NOÇÕES PRELIMINARES

Antes de enfrentar o enfoque principal deste trabalho, que pretende examinar a problemática pertinente aos esponsais, há que se analisar situações fáticas verificáveis no contexto existencial sociofamiliar que se antepõem necessária ou contingencialmente à promessa de matrimônio, que vêm tendo presença e efetividade no transcurso dos tempos, sob a categoria fático-jurídica de esponsais, ou até o próprio casamento. São os casos do namoro e do noivado, que se integram indissociavelmente ao núcleo familiar proclamado pela Lei Maior (Const. Federal, art. 226 “caput”), considerando a família "base da so- ciedade" e, como tal, conferindo-lhe a "especial proteção do Estado".

É de sentir-se que na atualidade não é mais permissível, como jamais foi refutado em tempos de outrora, que o primeiro evento fático a antepor-se à constituição da família, pelo matrimônio, e agora, em tempos atuais, também com a formação da união estável, é o namoro, que se singulariza por um acontecimento preliminar ou apriorístico de interação e enlevamento entre duas pessoas, geralmente de sexo oposto, que se sentem simultaneamente atraídas, uma pela outra, visando entre ambas a construção de uma convivência humana, harmoniosa e feliz, que poderá converter-se, no futuro, em noivado

1 Professor titular de Direito Civil no Curso de Pós-Graduação estricto sensu da Faculdade de Direito da UFRGS e no Curso de Direito, em nível de graduação, das Faculdades integradas São Judas Tadeu de Porto Alegre; Mestre e Doutor em Direito pela Universidade de São Paulo (USP). 
e até em promessa de casamento ou de união estável.

É a este conjunto de envolvimento familiar que se dá a denominação de esponsais.

Assim, deve-se ter presente que não só o namoro, como as demais situações fáticas dele decorrentes, na qualidade de comportamentos humanos, morais, habituais e sociologicamente inafastáveis, contribuem decisivamente para a formação da família. Essas posturas do ser humano vêm sendo apreciadas, especialmente, no que diz respeito ao casamento, desde tempos largamente recuados, por prelados e autoridades eclesiásticas através de encíclicas papais e, notadamente, a partir do Concílio Ecumênico de Trento (1.545 a 1.563). Mais recentemente, foram objeto da Encíclica Casti Conubii, expedida em 1930, pelo Papa Pio XI e que se encontram, na atualidade, positivadas na codificação canônica vigente de 1983, no cânon 1.062. São essas situações que vieram, pela sua condição social e humana, despertar a atenção da doutrina e de algumas legislações estrangeiras e, de igual modo, influenciar parcela da nossa doutrina e jurisprudência, como se verá adiante. ${ }^{2}$
Por outro lado, não se deve ignorar, por ser fato social ocorrente e notório, que vem se verificando com certa frequência no âmbito da sociedade atual, a situação fática da convivência íntima entre figuras humanas de mesmo sexo, a que a doutrina familista vem conferindo a designação de "uniões homoafetivas" ou "socioafetivas". ${ }^{3}$ É, sem dúvida, uma postura livremente eleita por seres humanos, que entre si convencionam, em caráter temporário ou permanente, uma vivência íntima em comum, para a qual elegem e proclamam como causa a comunidade de afetos. Cuida-se, à evidência, de fato tutelado indubitavelmente pelo direito fundamental de respeito à intimidade, que por essa razão deve receber, senão a aprovação integral da sociedade, mas a respeitabilidade dos demais convivas. Aliás, tal situação ainda não goza do beneplácito do direito positivo pátrio, mas é certo que aos interessados cabe invocar a jurisdição para colmatar a lacuna que, por razões outras, ainda existe na legislação e venha, desse modo, alcançar a tutela que tal caso tópico está a exigir posição jurisprudencial necessária, que pelos tribunais nacionais já vem sendo tomada.

2 HORTAL, Pe. Jesus. Código de Direito Canônico de 1.983 comentado. São Paulo: Edições Loyola, 1987, p. 469.

3 DIAS, Maria Berenie. Manual de Direito das Famílias. 3. ed. n. 16/17. São Paulo: RT, 2006, p. 30 e 32. 
É ainda oportuno registrar-se que o Supremo Tribunal Federal, em decisão recente, reconheceu constituir união estável a convivência postulada por pessoas do mesmo sexo, embora essa decisão contrarie a própria Constituição Federal (art. 226, § $3^{\circ}$ ) e a regra infraconstitucional estabelecida no artigo 1.723 da codificação civil de 2002 .

Há que se observar que namoro puro e simples representa situação fática que não recebe prioristicamente a tutela jurídica, razão pela qual essa falta de regulamentação legal não exige do casal a observância de requisitos para a sua formação, salvo os de ordem moral impostos pela sociedade e costumeiros observados por certa comunidade humana. Em especial, todavia, não deixa a sociedade de considerar que, para ser concebida como tal, na relação de namoro deve estar a convivência praticada pelo casal exornada com os atributos de fidelidade recíproca, da constância da relação e do conhecimento desta pelas pessoas que desfrutam de relacionamento mais próximo com os namorados. Mas também não se deve ignorar que em alguns relacionamentos íntimos, notadamente, nos chamados "relacionamentos abertos", abdiquem convencionalmente os membros do casal o requisito moral da fidelidade recíproca, embora tal dispensa se verifique em casos raros.

Assim sendo, tem se verificado nos últimos tempos, após à edição do Código Civil de 2002, a prática de ajustar entre os namorados contratos de namoro, com o objetivo de eximirem-se à qualificação de companheiros participantes de união estável, de vez que em caso de uma convivência mais duradoura, ou de coabitação sob o mesmo teto, quiçá ainda em face da publicidade da situação de namoro, poderá configurar-se dito instituto jurídico, se implementadas as linhas limítrofes previstas no artigo $1.723 \mathrm{da}$ codificação civil.

Helder Martinez Dal Col, em artigo publicado em agosto de 2005, após tecer, por um lado, extenso comentário acerca da família, dizendo-a existente “desde tempos imemoriais, constituída sob as mais variadas formas segundo os costumes de cada povo e influenciada pelos valores socioculturais, políticos e religiosos de cada época”, passa esse autor a analisar os requisitos necessários para a configuração da união estável com o objetivo de contrastá-la aos contratos de namoro, em torno dos quais realiza várias indagações para diversificá-los da dita relação jurídica instituída por lei e travada entre pessoas de sexo oposto.

No entanto, ditas formulações das hipóteses articuladas pelo autor são de tal amplitude e diversificação que dificultam a compreensão da doutrina e uma tomada de posição uniforme da jurisprudência, de modo que o propósito perseguido pelo articulista 
encontra obstáculos para escoimar as dúvidas sobre o assunto. ${ }^{4}$

Todavia, Alex Ravache, ao comentar a constituição do namoro e da união estável, formula prioritariamente a indagação: "Como saber se a relação configura um namoro ou uma união estável?”. E a seguir, analisando a formação do namoro, refere que:

O namoro não é conceituado pela lei. Se a lei não o regula, não há requisitos a serem observados para a sua formação, a não ser os requisitos morais, impostos pela própria sociedade e pelos costumes locais. Assim, em regra, os costumes e a moral nos trazem a ideia de que para uma relação ser considerada namoro, devem estar presentes a fidelidade recíproca, a constância da relação e o conhecimento do relacionamento por parte da família e dos amigos do casal. Nada impede, no entanto, que alguns relacionamentos quebrem essas regras morais. Existem namoros em que não há fidelidade, inclusive com a concordância mútua dos namorados em tal sentido. É o chamado relacionamento aberto. Esse fato, por si só, não desconfigura a existência da relação, que na prática existe e pode ser chamada de namoro ou um "mero caso”... Em suma, não há normas legais expressamente previstas para configuração do namoro.
Todavia, em outra passagem desse mesmo artigo de doutrina, ao tratar do contrato da constituição do namoro para diferenciá-lo da relação de união estável, afirma o ator ser importante salientar que:

o artigo 1723 do Código Civil é norma de ordem pública. Assim sendo, não é possível que o casal renuncie qualquer dos requisitos de formação da união estável, mesmo se ambos estiverem de mútuo acordo. Isso significa que o contrato de namoro não tem validade para evitar a configuração da união estável, a qual se constituirá com ou sem contrato, desde que os seus requisitos estejam, de fato, presentes. ${ }^{5}$

Como se vê, a doutrina predominante vem opondo restrições ao contrato de namoro, notadamente quando esse ajuste informal tem por objetivo impedir que o relacionamento entre os namorados venha se convolar em união estável. Paulo Lobo argumenta:

Em virtude da dificuldade para identificação do trânsito da relação fática (namoro) para a relação jurídica (união estável), alguns profissionais da advocacia, instigados por seus constituintes, que desejam prevenir-se de consequências jurídicas,

4 DAL COL, Helder Martinez. União estável e contratos de namoro no Código Civil de 2002. Jus navegandi. Teresina, ano 10, n. 759. Ago. 2005. Disponível em: <htt://jus. com.br/artigos/7100>

5 RAVACH, Alex. Diferença entre namoro e união estável. Jus Navegandi. Teresina, ano 16, n. 2768. 29 jan. 2011. Disponível em: <http://jus.com.br/revista/texto/18383>. 
adotaram o que se tem denominado "contrato de namoro". Se a intenção de constituir união estável fosse requisito para sua existência, então semelhante contrato produziria os efeitos desejados. Todavia, considerando que a relação jurídica de união estável é ato-fato jurídico, cujos efeitos independem da vontade das pessoas envolvidas, esse contrato é de eficácia nenhuma, jamais alcançando seu intento. ${ }^{6}$

A evidência, essa situação não tem campo fértil e bastante para verificar-se em relação ao matrimônio, em face das formalidades que, para a realização desse ato solene, são exigidos por lei, a começar pelo processo de habilitação (Cód. Civil, arts. 1.525/1.532) a ultimar-se com a celebração solene do casamento, de que dispõem os artigos 1.534 e 1.535 da codificação Civil de 2002.

\section{DA CARACTERIZAÇÃO E FORMAÇÃO DOS ESPONSAIS}

Embora a legislação brasileira não contenha dispositivo específico acerca do instituto dos esponsais, como se verá adiante, a nossa doutrina não o desconhece, e a jurisprudência o tem apreciado e tutelado em casos tópicos, sob o ângulo da responsabilidade civil. Mas, de qualquer maneira, vêm os esponsais recebendo a atenção da doutrina e de algumas legislações alienígenas como tema de atualidade, a partir da consideração de que todo casamento é sempre precedido de uma promessa de realização futura. ${ }^{7}$

Chegam até alguns tratadistas de direito civil, como Josserand, pertinentemente ao casamento, a afirmar que:

não se concebe casamento sem esponsais, isto é, sem projeto, sem promessas recíprocas prévias, pois pela própria força das coisas, decorre sempre um certo prazo entre o momento em que os nubentes, um ao outro, se prendem pelo amor e aquele em que este recebe a consagração oficial. ${ }^{8}$

Etimologicamente, a expressão “esponsais” deriva do vocabulário latino sponsio, que significa promessa solene, e sponsalia, a sua realização, banquete de núpcias, que entre nós leva a denominação de noivado.

Diante dessa visão semiológica, pode-se definir os esponsais como ato preparatório para o casamento (diga-se também para a união está-

6 LOBO, Paulo. Direito Civil - Famílias, 2. ed. São Paulo: Saraiva, 2009, p. 156.

7 ESPINOLA, Eduardo. A Família no Direito Brasileiro. v.4. Rio de Janeiro: Editora Conquista, 1957, p. 37; CHAVES, Antonio. Lições de Direito Civil. Direito de Família. v.I. São Paulo: Editora RT, 1974, p. 37.

8 JOSSERAND, Louis. v.I. n. 740. Cours de Droit Civil, Paris: L.G.D.J., 1955. 
vel) livremente convencionado pelos namorados ou pelos noivos, a ser realizado no futuro, com ou sem estipulação de prazo.

De fato, encontram-se abundantemente manifestadas pela doutrina e por algumas legislações alienígenas as preocupações com a situação fático-jurídica dos esponsais que pode converter-se em promessa de casamento ou de união estável e que, descumprida por um dos promitentes, pode resultar ao outro desconforto pessoal ou prejuízo material e moral ressarcíveis pelo descumpridor da promessa.

De modo geral, existe parte da doutrina e até da jurisprudência que defende a posição de consenso de que os esponsais apresentam espectro amplo, sendo formados conjuntamente pelas situações fáticas do namoro, do noivado e das promessas de casamento ou de união estável. Ou seja, forma-se por essa corrente harmoniosa, mediante a qual dois seres humanos se unem por uma atração física ou enlevamento despertado entre ambos para desfrutar uma convivência humana harmoniosa e feliz, que inicialmente se constrói pelo namoro, se amplia pelo noivado e se aperfeiçoa pela promessa recíproca na qual se estabelece a perspectiva futura de constituição de matrimônio ou de união estável.
No entanto, há que se convir haver também parcela da doutrina e da jurisprudência que dá enfoque jurídico apenas ao suporte fático da promessa de casamento ou de união estável. Essa parcela leva em consideração somente esse comprometimento dos enamorados para ser admitida e caracterizada como esponsais e, consequentemente, como categoria jurisdicizível. Se assim for considerada, procede-se a aferição do cumprimento ou não da promessa convencionada pelos compromitentes.

Esse modo de proceder não deixa de ter consonância com a doutrina canonística que se encontra positivada no Código de Direito Canônico de 1983, promulgado pelo Papa João Paulo II, com a expedição da Constituição Apostólica Sacrae Disciplinae Leges, de 25 de janeiro de 1983, cujo cânon 1.062 e seus parágrafos 1 e 2, têm a seguinte redação:

Canon $1062-\S 1$. A promessa de matrimônio, tanto unilateral como bilateral, denominada esponsais, rege-se pelo direito particular estabelecido pela Conferência dos Bispos, levando-se em conta os costumes e as leis civis, se as houver. $\S 2$. Da promessa de matrimônio não cabe ação para exigir a celebração do matrimônio, mas cabe ação para reparação dos danos, se for devida. ${ }^{9}$

9 HORTAL, Pe. Jesus. Código de Direito Canônico de 1.983 comentado. São Paulo: Edições Loyola, 1987, p. 469. 


\section{DA NATUREZA JURÍDICA DOS ESPONSAIS}

Tema deveras controvertido, que estabelece significativo foco de divergência entre a doutrina, é a natureza jurídica dos esponsais.

Gravita entre os doutrinadores extensa discussão sobre se os esponsais apresentam natureza contratual ou apenas configuram uma relação de fato, sem pertinência jurídica.

Segundo a lição de Antonio Chaves, inúmeras têm sido as teorias construídas pelos juristas a respeito dos esponsais, ao referir o que grassa nessa discussão:

Desde as que a têm na conta de simples relação de fato, até as que querem estreitá-la nas braçadeiras de ferro de um verdadeiro contrato. ${ }^{10}$

E conclui esse autor, na esteira dos ensinamentos de Giampaolo Novara, que a natureza jurídica da promessa de casamento não pode ser considerada senão no âmbito das negociações précontratuais, pelas razões seguintes:

A exigência social de garantir plena a liberdade na realização do matri- mônio leva a simplificar a promessa de casamento, reduzindo-a da sua natureza inicial de negócio a um simples ato voluntário. Por outro lado, para que a promessa de casamento não fique completamente desprovida de proteção jurídica, deve ser levada em conta a situação de fato determinada pelo noivado e pelas negociações pré-matrimoniais. ${ }^{11}$

Essa posição de Giampaolo Novara, referida por Antonio Chaves, é também defendida por Eduardo Espínola, que assim se manifesta:

Nada mais artificial e contrário à verdade das relações sociais do que a afirmação de serem nulas as promessas de casamento. Não valem como contratos efetivamente constituídos, não produzem a obrigação jurídica de fazer o prometido ou satisfazer multas convencionais; constituem, todavia, um período pré-contratual, que autoriza os noivos a despesas e determinações especiais, tendo em vista enlace projetado. É conforme a equidade e os princípios gerais de direito que a parte de boa-fé, prejudicada com o procedimento injusto da outra, seja indenizada dos prejuízos que efetivamente verifique, por haver acreditado que o contrato matrimonial se realizaria. ${ }^{12}$

10 NOVARA, Giampaolo. La promessa de matrimonio. Gênova, L.V.P.A., 1950, p. 10 apud CHAVES, Antonio. Quebra da promessa de casamento - devolução dos presentes de noivado. Revista Forense. v. 228, p. 59-67, 1969.

11 NOVARA, Giampaolo, ob. cit. p. 60.

12 ESPÍNOLA, Eduardo - Tratado de Direito Civil, v. VIII B, p. 761 apud RIBEIRO, Fausto Couvert - Os esponsais. Institia v. 53, ano XXVIII, 1966, p. 68-69; CHAVES, Antonio - Quebra de promessa de casamento - devolução dos presentes de noivado, ob. cit. p. 61. 
Ao tratar do casamento, no § 764 do seu Tratado de Direito Privado, com referência aos esponsais, Pontes de Miranda assim se manifesta:

O casamento de que tratamos é o casamento que o Código Civil e as leis posteriores regulam. Deixamos de nos referir aos esponsais, porque, como instituto de direito de família, foram excluídos do nosso direito. Isso não quer dizer que não exista lugar, no direito das obrigações, para os contratos esponsalícios. Se o método de interpretação do direito de família não nos permite construir, em tal ramo jurídico, instituição a que se não fez qualquer referência, não ocorre o mesmo quanto ao direito das obrigações, onde o princípio da autonomia da vontade e da livre arquitetação contratual domina visivelmente. A doutrina sempre pôs em relevo o contrato de direito das obrigações e o contrato de direito de família que se contém nos esponsais. Alguns povos os qualificam pelas duas faces. Outros somente por uma. Desde que não ofenda os bons costumes, é possível, no direito brasileiro das obrigações, o contrato esponsalício) bem como, em certas circunstâncias, a indenização por ato ilícito, com base na promessa de casamento" (grifou-se). ${ }^{13}$

Assim sendo, há que se concluir, com Pontes de Miranda, que os espon- sais configuram, pelo menos no direito brasileiro, um pré-contrato ou contrato preliminar de direito de família, que recebe a tutela do direito das obrigações, quando, na sua execução resultar ilícito civil por descumprimento de um dos promitentes, em prejuízo do outro, aplicando-se, no caso, as disposições dos artigos 186 e 927 da codificação civil de 2002, aliás, como já ocorria na vigência do da codificação revogada, com fundamento no seu artigo 159. Todavia, nas legislações estrangeiras, analisar-se-á adiante a natureza jurídica dos esponsais.

\section{OS ESPONSAIS NA HISTÓRIA E NO DIREITO COMPARADO}

Os esponsais, como instituição que se integra no contexto familiar, figurando como antecedente necessário ou contingente na formação da família, percorre os mesmos passos do ente familiar no andar dos tempos, bem como vêm descortinar sua presença em alguns sistemas jurídicos internacionais, como se verá a seguir.

Como primeiro passo para desempenhar esse mister, não seria de bom alvitre deixar de referir aqui a exata, excelente e providencial classificação dos esponsais nas codificações

13 PONTES DE MIRANDA - Tratado de Direito Privado, Tomo VII, 3764, p. 200201, Edição Borsoi, Rio de Janeiro, 1971. 
estrangeiras que acolhem ou não o instituto, realizada pelo Professor Doutor Eduardo de Oliveira Leite, da Universidade Federal do Paraná. Eis o texto integral da mencionada classificação:

Em matéria de regulamentação do tema das promessas de casamento, é possível distribuir-se as legislações em quatro classes: I - À primeira, pertencem os códigos que veem nos esponsais um verdadeiro contrato. O seu inadimplemento gera a plena obrigação de indenizar. Os exemplos típicos desta tendência materializamse nos códigos, alemão, suíço e anglo-americano. II - À segunda classe filiam-se os códigos que não vislumbram nos esponsais qualquer manifestação contratual. Deles não resulta a obrigação de casar, nem a de satisfazer penas estipuladas, reconhecendo, porém, a possibilidade de indenização à parte repudiada. São representantes desta categoria os Códigos austríaco, espanhol, português e italiano. $\mathrm{Na}$ América, seguiram esta tendência os Códigos mexicano, peruano e venezuelano. III - À terceira classe, à qual o Brasil se filia, omite qualquer disposição concernente aos esponsais. É igualmente a situação dos Códigos francês e romeno. IV - À quarta categoria jurídica não silencia sobre os esponsais, mas declara expressamente que a lei não reconhece os esponsais, nem admite qualquer ação de indenização por prejuízos deles resultantes. Como ato privado que é, encontra seus ditames e limites na honra e consciência pessoais. A esta classe pertencem os Códigos argentino, uruguaio e chileno. ${ }^{14}$

Como se pode constatar, a classificação dos esponsais realizada pelo Professor Eduardo de Oliveira Leite, acima transcrita, é exata e deveras esclarecedora, pois exerce o papel de tornar claras as divergências que militam na doutrina e nas legislações, tanto nas que seguem o sistema romano-canônico ou europeu-continental, integrantes da chamada Família Civil Law, quanto nas demais, seguidores do sistema Common Law. Esclarece, inclusive, o Professor articulista, as principais particularidades praticadas no exercício do instituto, por aqueles sistemas que o contemplam.

Agora, recuando no andar dos tempos, deve-se examinar, senão antes, por efetiva escassez de registros históricos, mas, pelo menos, a partir da antiguidade clássica, a começar pela presença dos esponsais no sistema romano.

No direito romano, os esponsais, então derivados da expressão latina sponsalia, indicavam o contrato ou a convenção que precedia o matrimônio, em virtude do qual os noivos

14 LEITE, Eduardo de Oliveira. Rompimento da Promessa de Casamento - Reparação dos Danos Material e Moral. Revista Ajuris. p. 70, n. 51, ano XVIII. março de 1991. 
ou futuros esposos assumiam por si mesmos ou por intermédio de seus pais o compromisso ou promessa de se casar no futuro. A denominação de sponsalia, atribuída ao ato pelo sistema romano, era derivada da forma pela qual os noivos objetivavam uma estipulação (estipulatio) que servia de garantia (sponsio) à promessa que, descumprida por um dos sponsi, permitia ao outro razão para reclamar seu direito, mediante a propositura da actio ex sponsu. ${ }^{15}$

Segundo a doutrina de Clovis Bevilaquia, o instituto dos esponsais no direito romano não apresentava todas as características que estão presentes nos editos da modernidade. Eis o que refere Clovis:

A palavra esponsaes nos veio do direito romano (sponsalia dicta sunt a spondendo) e significa, em direito moderno, o contrato pelo qual duas pessoas de sexo diferente se prometem uma à outra em casamento. Sunt mentio et repromissio futurarum nuptiarum, definiu Florentinus (D. 22, 1, fr. 1).

Si estudarmos a história do instituto, veremos que elle nem sempre foi promessa recíproca, tendo apresenta- do diversas phases em sua evolução, a qual, depois de completar-se, se vae hoje tornando accelerada involução senil.

Devemos considerar este pacto uma transformação da compra das mulheres para o casamento. A princípio realizou-se entre o grupo familial do noivo e o da noiva ou entre os chefes das respectivas famílias, e, só mais tarde, apresentou-se em forma de contracto realizado entre os futuros consortes, para reduzir-se, em alguns systemas jurídicos, a um simples ajuste de casamento que não transpõe, sinão directamente, as raias das relações extra-judiciaes. ${ }^{16}$

Certamente, quando o autor se refere acima à "compra das mulheres para o casamento”, está a referir-se à modalidade de casamento denominada coempio, a qual se realizava na forma de uma compra e venda em que o noivo adquiria a noiva do poder familiar a que esta estava subordinada. Certamente é por essa razão que os romanistas a denominavam uma imaginaria venditio essa forma de união matrimonial. ${ }^{17}$

Noticia também Bevilaqua outra experiência acerca da realização

15 DE PLÁCIDO E SILVA. Vocabulário Jurídico. 15. ed. Rio de Janeiro: Forense, p. 318.

16 BEVILAQUA, Clovis. Direito de Família.Recife: Ramiro M. Costa \& Cia., 1896, p. 11-12.

17 MOREIRA ALVES, José Carlos. Direito Romano. v. II. 5. ed. n. 278. Rio de Janeiro: Forense, 1995, p. 314-5. 
dos esponsais mediante a compra de mulheres, nos seguintes termos:

Os anglo-saxões, transportando-se para a Inglaterra, não olvidaram o costume de contrair esponsaes, pois sistema do "pretium uxoris", sendo o instituto minuciosamente regulado por uma lei atribuída a Edmundo. ${ }^{18}$

No antigo direito romano, no período transcorrido entre a fundação de Roma no ano 753 a.C. e que se estendeu até o advento de Lex Albutia, denominado período pré-clássico, os esponsais se realizavam mediante um contrato de promessa de matrimônio futuro entre duas pessoas de sexo diferente, que se realizava por meio da sponsio do pater da mulher prometida. Essa obrigação nascida da dita promessa, quando descumprida, era passível de exigência judicial por meio da actio ex sponsu, contra o sponso descumpridor da obrigação. ${ }^{19}$

No período clássico, que transcorreu a partir da Lex Aebutia surgida aproximadamente no ano 120 a.C., até o fim do reinado de Diocleciano, em 305 d.C., no ato de realização dos esponsais passa a ser dispensável o requisito de forma, não podendo ser exigido judicialmente o seu cumprimento, nem mesmo para obter a pena previamente ajustada para a hipótese de inadimplemento, eis que era considerado ato ilícito qualquer atitude de limitação à liberdade de contrair matrimônio. Em razão dessa proibição, a promessa poderia ser rescindida livremente, sem qualquer ônus para o contratante arrependido. ${ }^{20}$

Já no período pós-clássico do sistema romano, transcorrido a partir do final do reinado de Diocleciano, em 305 d.C., até o falecimento de Justiniano, em 565 d.C., as disposições do Imperador Constantino, que se convertera ao catolicismo no Edito de Milão (313 d.C.), estabeleceram a sujeição das doações recíprocas entre os noivos à condição tácita de conversão da promessa em casamento. Todavia, se a noiva houvesse sido beijada no ato do noivado e o noivo viesse a falecer, ela teria direito de manter para si a metade do que lhe havia sido doado. Ainda nesse período pós-clássico foi recepcionado pelo

18 BEVILAQUA, Clovis. Ob. cit., p. 13.

19 ASCARCELLA, Agatina Stefania. Libertá. p. 4. Matrimoniale e stipulatio poena studia et Documenta Historiae et iuris. v. LXVI. p. 149-50, 2000.

20 VIERO, Ângela Cristina. Esponsais - Evolução (ocaso?) História e Lineamentos Atuais do Instituto do Direito Brasileiro e Comparado. p. 4. Seminário apresentado no encontro de doutorandos e mestrandos da UFRGS, no semestre 2011/2. 
sistema romano o instituto das arrhae sponsaliciae, que representava dação recíproca de somas de dinheiro entre os noivos a título de garantia da promessa de casamento. Em tal situação, a parte descumpridora da promessa, sem razão justa, perdia a soma de dinheiro entre ambos arbitrada e restava obrigada a restituir, em primeiro momento, o quádruplo do que havia recebido e, posteriormente, no período justinianeu (525 a 565 d.C.), o dobro ou apenas o mesmo valor recebido, se de menor monta. ${ }^{21}$

Assim, primitivamente nas cidades do Lácio, os esponsais eram celebrados por meio da sponsio, que desfrutava a qualificação de negócio jurídico verbal e solene, adotando as seguintes denominações: sponsalia: significando esponsais; sponsa: a mulher prometida; e sponso: o homem prometido. Ainda gozava da eficácia jurídica plena de tal modo que se uma das partes descumprisse a promessa, a outra restava legitimada para propor a actio ex sponsu, para postular indenização e haver o ressarcimento do dano sofrido. No transcurso da evolução do direito romano, os esponsais sofreram importantes transformações. Assim, no direito clássico, sua importância ficou reduzida quase que exclu- sivamente ao aspecto social, enquanto que nos períodos pós-clássico e justinianeu, tiveram os esponsais mais elevados os seus efeitos jurídicos, já que os sponsi ou prometidos, sob certos aspectos,tornaram-se equiparados aos cônjuges. ${ }^{22}$

Quanto aos efeitos, embora os esponsais não obriguem as partes, mantendo-se, desse modo, a liberdade dos sponsi da manifestação de vontade para o casamento, geram uma quase adfinitas entre cada um dos sponsi e os parentes do outro, decorrendo, daí, impedimentos matrimoniais, bem como a dispensa do dever de prestar depoimento em juízo contra o sponsus ou os futuros sogro e sogra; impede a conclusão de outros sponsais ou de casamento, antes do rompimento dos esponsais anteriores; ainda, no direito pós-clássico, a infidelidade da sponsa é punida com as penas do adultério. ${ }^{23}$

No âmbito do direito canônico, foram mantidas algumas características dos esponsais, que já haviam sido adotadas na esfera do direito romano, frutos da própria evolução ocorrida nesse sistema. Entre tais modificações, a liberdade de forma, por seu particular relevo, tornou-se mais simplificada e, do mesmo modo, por não ser de maior importância, tornou-

21 VIERO, Ângela Cristina. Ob. cit. p. 5.

22 MOREIRA ALVES, José Carlos. Ob. cit., p. 335.

23 MOREIRA ALVES, José Carlos. Ob. cit., p. 337. 
se também menos rigorosa a imposição de penas convencionais em geral, particularmente, quanto ao modo de executar as arrae sponsalitiae. Ainda, ocorreu um maior abrandamento quanto à exigência no que se refere às doações ajustadas entre os noivos, na hipótese da promessa de casamento. Mas não se esgotam aí as nuances especiais pertinentes aos esponsais, no âmbito do sistema canônico, como adiante será explicitado.

É sabido que em Roma, para atuar e resolver os litígios emergentes das relações de natureza civil, havia os procedimentos próprios das legis actiones, divididas em cinco ações: da legis actio per sacramentum, da legis actio per indicis arbitrive postulationem, da legis actio per condictionem, da legis per manus iniectionem e da legis actio per pignoris capionem. Enquanto no processo formulário agere per concepta verba, instituído a partir da Lex Aebutia editada aproximadamente no ano 120 a.C., foram substituídas as actiones legis do sistema anterior pelas fórmulas do pretor (urbanus em 360 e peregrinus em 240
a.C.), havendo nelas como novidade a litis contestatio, realizada pelo pretor com as partes litigantes e que tinha a natureza de uma novação, porquanto transformava a lide originária, discutida pelas partes, em uma nova lide a ser resolvida pelo iudex, pessoa do povo distinta do pretor. No sistema posterior ao agere per formulas, denominado de extraordinária cognitio, o procedimento desenvolvia-se inteiramente pelo magistrado imperial investido da iurisdictio. ${ }^{24}$

Pois bem, nesses períodos referidos acima, havia em Roma dois tipos de ação e procedimento para atuar e resolver os litígios: no campo das relações civis, as ações e os juízos suprarreferidos; para atuar e resolver as demandas no âmbito do sistema canônico, especificamente resultantes do descumprimento dos esponsais, a actio ex sponsu a ser resolvida pelo juízo da episcopalis audientia, ou tribunal do Bispo.

Todavia, o imperador Constantino, que sucedeu a Diocleciano e assumiu a governança do Império Romano de 306 a 337 d.C., converteu-se

24 NORONHA, Carlos Silveira. Sentença Civil Histórico-dogmático. Revista dos Tribunais 6.2, 6.3 e 6.4, p. 11-130, São Paulo, 1995; GAIO. Instituciones. Traduçao do espanhol, Manuel Abellan Velasco e outros, Madrid: Edición Civitas, 1985, p. 307-9; SCIALOJA, Vittorio. Corso di Institrigioni di Diritto Romano. Roma: Ed. Anônima Romana Editoriale, 1934, p. 195-6; CANNATTA, Carlo Alberto. Profilo Instituzionali Del Processo Privato Romano, II. Il Processo Formolaere. Turin: Ed. Giappichelli Editore, 1982; LUZZATTO, Ignazio. Il Problema D'Origine Del Processo Extra Ordinem. Bolona: Ed. Casa Editrice Prof. Riccardo Petron, 1965, p. 15-6. 
ao cristianismo no Edito de Milão de 313 d.C., quando, segundo os historiadores, deu a paz à Igreja Católica, da qual ainda não havia anteriormente gozado. Com a outorga da constituição do ano 318 d.C., transformou o tribunal eclesiástico da episcopalis audientia, vigente no sistema canônico desde os primeiros tempos, em instituição pública, reconhecendo-a não só como órgão jurisdicional de direito canônico como também do Estado Romano, operando-se com esse ato profunda transformação na jurisdição eclesiástica, quando três consequências importantes desse ato decorreram; pela primeira, era estendido o conhecimento e a resolução dos litígios emergentes das relações civis pela episcopalis audientia out, sempre que o interessado por esse optasse, ainda que o pedido fosse só de uma das partes; pela segunda, estava excluída a jurisdição estatal para o processo e julgamento das causas eclesiásticas, ainda que as partes a postulassem; pela terceira, a decisão eclesiástica tornou-se inapelável. ${ }^{25}$

Não são particularmente identificáveis disposições canônicas acerca dos esponsais, a partir da época pós-clássica, até os tempos das promulgações das duas edificações oficiais de 1917 e 1983, apesar de haverem sido expedidos, por exemplo, o Decreto de Graciano (1140), as Decretais de Gregório IX (1234), o Líber Sertus, de Bonifácio VIII (1298), a Clementina Saepe Contingit, de Clemente V (1314), todas elas, a exceção do Decreto de Graciano, reunidas por um jurista francês, chamado Giovanni Chappuis, e publicadas na consolidação denominada Corpus Iuris Canonici, na edição parisiense de $1500 .^{26}$

Como se pode constatar, os esponsais só voltaram a ser tratados com efetividade nas codificações canônicas oficiais de 1917 e 1983.

A anterior codificação canônica de 1917, promulgada pelo Papa Bento $\mathrm{XV}$, no dia de Pentecostes, pela Constituição Providentíssima Mater Eclésia, de 27 de maio de 1917, já disciplinava no cânon 1.017 a promessa de casamento ou esponsais, tanto unilateral como bilateral, que era considerada nula, se não se realizasse por meio de escritura firmada pelas partes e, ainda, pelo Pároco ou Ordinário do lugar e duas testemunhas. ${ }^{27}$

Já o vigente Código Canônico de 1983, promulgado pelo Papa João Paulo II, publicado pela Constituição Sacrae Disciplinae Leges, de 25 de janeiro de 1983, que entrou em vi-

25 NORONHA, Carlos Silveira. Ob. cit. n. 7.4, p. 155.

26 NORONHA, Carlos Silveira. Ob. cit. n. 77, p. 174.

27 CABREROS DE ANTA, Marcelino et al. Código de Derecho Canônico de 1917. Madrid: Ed. Biblioteca de Autores Cristianos, 1974, p. 390. 
gor a 27 de novembro de 1983, preceituou no cánon 1.062, parágrafo 1 , que a promessa de matrimônio, tanto unilateral como bilateral, denominada esponsais, rege-se pelo direito particular estabelecido pela Conferência dos Bispos, levando-se em conta os costumes e as leis civis, se as houver. E no parágrafo 2, desse cânon, dispõe que da promessa de matrimônio não cabe ação para exigir a celebração do matrimônio, mas cabe ação para reparação dos danos, se for devida.

Como se verifica pela regra expressa existente no cânon 1.062, parágrafo 2 , da codificação canônica vigente, embora se contenha expressa ou implicitamente no pré-contrato de esponsais a cláusula denominada pela doutrina canônica sponsalia de praesenti, ou sponsalia per verba de praesenti que obrigaria a realização do matrimônio, tal comprometimento dos noivos não é exigível no cumprimento da promessa, como o era por meio da actio matrimonialis no passado, segundo a cânon 1.017, parágrafo 3, do Código canônico de 1917, tendo em vista que a posição da canonística é no sentido de que a realização do casamento válido exige a livre manifestação de vontade de ambos os nubentes de receberem por marido e mulher. ${ }^{28}$
Desse modo, deve subsistir a outra cláusula denominada sponsalia de futuro ou sponsalia per verba de futuro, na qual se consubstancia a obrigatoriedade de um dos promitentes de ressarcir o outro de eventuais prejuízos causados a este, no caso de rescisão unilateral dos esponsais, aplicáveis, na hipótese, às regras de reparabilidade de danos, estabelecidas pelo respectivo sistema jurídico estatal, se for o caso. Seguem tal entendimento originário do direito canônico, este que vem sendo praticado pela canonística desde tempos sobremaneira recuados. Vem, de igual modo, influenciando de maneira determinada os sistemas jurídicos estatais que parcial ou integralmente contemplam em seus editos os esponsais.

No que diz respeito à presença ou não do instituto dos esponsais nas ordens jurídicas estrangeiras, deve-se voltar, de modo breve, à excelente classificação realizada pelo Professor Eduardo de Oliveira Leite, dividindo-as em quatro classes, como já se viu acima. Incluídos estão na primeira classe os sistemas jurídicos que consideram os esponsais um verdadeiro contrato e, consequentemente, o seu descumprimento causa reparação do dano pelo respectivo responsável, tais 
como as codificações alemã, suíça e anglo-americana; a seguir, na segunda classificação, estão arrolados os códigos que negam reconhecimento jurídico ao dito instituto, mas preveem, em certos casos, indenização ao promitente desprezado pelo descumpridor do compromisso, situando-se nessa categoria os códigos austríaco, espanhol, português, italiano, mexicano, peruano e venezuelano; à terceira classe filiam-se os sistemas jurídicos que omitem qualquer referência aos esponsais, em que estão alinhados os códigos francês, romeno e, bem assim, o brasileiro; e, por último, estão os sistemas que, ao se referir aos esponsais, declaram que as suas leis não os reconhecem como categoria jurídica autônoma e, por consequência, não contemplam qualquer tipo de ação indenizatória de eventuais danos deles resultantes. ${ }^{29}$

Dentre os sistemas jurídicos estrangeiros que, de modo geral, tratam dos esponsais está o direito alemão, o qual, no particular, é seguido com estreitas semelhanças pelos sistemas suíço e anglo-americano. ${ }^{30}$

Pelo direito germânico, os esponsais são acolhidos na qualidade de um verdadeiro contrato de direito das obrigações que surte efeitos no direito de família, em razão do que descumprida unilateralmente por uma das partes essa relação contratual de modo a causar prejuízo a outra, a esta é reconhecida legitimidade para reclamar a reparação dos prejuízos sofridos. Figuram, assim, os esponsais como um compromisso matrimonial contraído pelos noivos, cuja natureza jurídica configura um contrato obrigacional que surte efeitos reflexos no direito de família.

Sobre o assunto, transcreve-se abaixo a manifestação de Theodor Kipp, que amplamente se manifesta sobre os esponsais, a começar pelo conceito e pela história desse instituto e esclarecer seu tratamento pelo sistema germânico, como a seguir:

Por esponsales se entiende tanto el convenio de futuro matrimonio entre um hombre y uma mujer como la relación producida por este coveinio (el noviazgo) em los tiempos del matrimonio por rapto, del qual se advierten todavia las huellas em los derechos germânicos, los esponsales, según parece, eram desconocidos. Después del tránsito el matrimonio contractual (matrimônio por compra), aparece em concepto de esponsales um contracto bilateral de derecho de obligaciones (celebrado antes de la benedición nupcial) entre los titulares de la potestad sobre la mujer y el novio y que obliga a los primeros a transmitir la Munt mediante la

29 LEITE, Eduardo de Oliveira. Ob. cit., p. 70.

30 LEITE, Eduardo de Oliveira. Ob. cit., p. 70. 
traditio puellae $\mathrm{y}$ al segundo a tomar como mujer a la novia y a una contraprestación. El novio puede constreñir al promitente a la tradición de la novia. La coacción al casamiento ejercida contra la novia no deriva de la promessa, in la que no há tomado parte, sino de la Munt o potestad a que está sumetida. Además, era fecuente que el novio corroborasse la fidelidad de la novia haciendola personalmente un presente, por ejemplo, un anillo de oro, cuya aceptación obligaba a la novia. Los esponsales del derecho alemán no establecen solamente una relación de derecho de obligaciones, sino también de derecho de família. El noviazgo produce ciertos efectos de derecho personal em concepto de efectos prévios del matrimonio: la ruptura de los sponsales es tratada de uma manera parecida al adultério; el novio tiene pretensiones de indemnización (Busse) contra teceros que se casen con la novia, la rapten o lesionen; el novio está obligado a contribuir al rescate cuando ella es librada de las manus de los enemigos. Los esponsales, que están sujetos a determinadas formas, son parte essencial del negocio de conclusión del matrimonio. ${ }^{31}$

Ainda refere Theodor Kipp, em seu extenso relato sobre os esponsais, que:
Com el triunfo de la jurisdicción matrimonial eclesiástica sobre la secullar también quedan suplantadas por las normas eclesiásticas de los esponsales las de derecho alemán”. Del derecho romano tomo el concepto de los esponsales (sponsalia, sponsalia de futuro, em contraposición a la celebración del matrimonio, sponsalia de praesenti) como promessa bilateral de matrimonio. ${ }^{32}$

Acerca da natureza jurídica perante o direito germânico, assim se manifesta Theodor Kipp, ao referir:

A los esponsales son un contrato de drecho de obligaciones y de derecho de família - Son contrato de derecho de obligaciones (promessas de matrimônio). Los prometidos se obrigam a contraer matrimonio entre ellos. Sin embargo, este deber no engendra acción judicial y no puede reforzarse mediante pena convencional, pues la conclusión del matrimonio debe ser libre (§ 1.297). Los esponsales determinan para cada una de las partes um deber subsidiário de indemnización si resuelve el contrato sin causa o si por su culpa da lugar a la resolución por la otra parte.

Em segun lugar, aunque se limiten a preparar el matrimonio, de los

31 KIPP, Theodor. In: ENNECERUS, Ludwig; WOLFF, Martin. Tratado de Derecho Civil. Cuarto Tomo: Derecho de Família. Trad. Espanhola, 2. ed. BOSCH, Casa Editorial S.A., 1953, p. 25-6.

32 KIPP, Theodor. Ob. Cit., p. 26. 
esponsales derivan ciertos efectos de derecho personal del matrimonio mismo. Por tanto, los esponsales aparecen como una relación familiar de naturaleza especial. En particular el prometido es "familiar" en el sentido del Código penal, ló cual tiene importância ante todo para exención de la pena em caso de estado de necesidad o cumplicidad. Por el contrario, en los esponsales faltan, como la plena comunidad de vida, los efectos patrimoniales del matrimonio. Los prometidos no tienen reciprocos derechos a sucederse por la ley, ni cuota de legitima. A diferença del antiguo derecho alemán, los esponsales no son ya parte integrante del acto de conclusión del matrimonio. Puede contraerse matrimonio valido sin esponsales prévios, y los vícios de éstos no son vícios del matrimonio. ${ }^{33}$

Em derradeiro, após manifestarse longamente acerca dos esponsais e o faz certamente porque é o direito germânico o sistema jurídico que considera o instituto um verdadeiro contrato de direito das obrigações, com efetivos reflexos no direito de família, como se viu acima, aborda, por fim, o iminente jurista teuto, Theodor Kipp, as causas de extinção dos esponsais, como a seguir se refere:

Los esponsais se extinguem: Per cumplimiento del deber que estable- cen, o sea por conclusión del matrimonio de los prometidos entre si. Si el matrimonio es nulo o impugnable, queda aún la posibilidad de que los esponsales sean válidos, a saber: si todavia es posible la conclusión de um matrimonio válido.

Los prometidos pueden disolver los esponsales mediante contrato de extinción. Si el contrato es nulo, no podrá por lo regular ser considerado como resolución unilateral, pues quien resuelve unilateralmente, dado su deber de indemnizar, es de peor condición que el que deja sin efecto los esponsales de acuerdo com la outra parte.

Todos los esponsales se extinguen en virtud de resolución por una de las partes. La resolución es una declaración de voluntad unilateral, recepticia y no sujeta a forma, que se dirige al outro prometido.

El compromisso matrimonial se extingue, finalmente, por imposibilidad subsiguiente o, lo que es igual, por falta de oportunidad para el cunplimiento. Tales son los casos, ante todo, de muerte de uno de los prometidos, de pérdida de la capacidad para celebrar negocios jurídicos, de posterior aparición de un impedimento indispensable: como si uno de los prometidos contrae matrimonio com tercera persona o incurre con el otro prometido en affinitas illegitima. La imposibilidad puede basarse en la culpa de uno de los prometidos. Tal sucede cuando contrae matrimonio con tercera persona. Entonces está obligado

33 KIPP, Theodor. Ob. cit., p. 31-2. 
a indemnizar (§ 280). Pero el alcance de la indemnización se determina na La analogia de lós $\S \S 1.298$ ss. ${ }^{34}$

Os sistemas jurídicos da Áustria, da Espanha, de Portugal, da Itália, na Europa continental, os hispano-americanos do México, do Peru e da Venezuela não tratam dos esponsais como categoria jurídica formadora de uma relação contratual. Por essa razão, não reconhecem em suas codificações legitimidade aos integrantes de uma relação de namoro ou de noivado ou até de compromisso de matrimônio, para pretenderem o cumprimento de uma promessa de casamento, nem mesmo conferem direito à parte enganada para haver indenização, pela outra, dos prejuízos que eventualmente haja sofrido pelo descumprimento unilateral desse compromisso por ambos ajustado. É o que, entre outros, entende o Professor Eduardo de Oliveira Leite, no seu trabalho de excelente classificação dos esponsais. ${ }^{35}$

As codificações civis da França e da Romênia não conferem aos esponsais categoria jurídica própria. Todavia, em face de algumas manifestações paralelas acerca do instituto no sistema francês, notadamente nas Lições de Mazeaud, passaremos a registrá-las de pronto, enquanto que sobre o tratamento do instituto no direito brasileiro, o faremos na parte final deste trabalho acadêmico.

Inicia Mazeaud sua manifestação doutrinária abordando o conceito, a natureza jurídica e a ruptura dos esponsais, na perspectiva do sistema francês.

Utilizando-se de tal metodologia, assim se manifesta o mencionado autor:

La promesse de mariage ou fiançailles, se distingue du mariage; le mariage implique l'intention de se prendre pour mari et femme immediatement (sponsalia de presenti); les fiançailles dans l'avenuir (sponsalia de futuro). On prend souvent come synonymes les expressions promesse de mariage" fiançailles". Il existe cependant une nuance. La promesse de mariage (strito sensu) designe, l'échange des volontés. Les fiançailles (stricto sensu) comportent outre cet élément intentionnel, un élément de publicité: l'annonce de la promesse, faite aux parent et aux relations. La distinction présente parfois un intérét, on aura l'accasíon de le précíser.

Dans l'auscien, droit, les fiancailles étaint un contrat veritable qui ne pouvait pas être rompu unilatéralement au gré de l'un des fiancés; le fiancé qui rompait engageait sa responsa-

34 KIPP, Theodor. Ob. cit., p. 40-8.

35 LEITE, Eduardo de Oliveira. Ob. cit., p. 70. 
lilité. Par les fiançailles, chacun des fiancés a promit à l'autre le mariage; l'obligation qu'il a ainsi contractée doit être exécutée. Les rédacteurs du Code Civil ayant gardé le silence sur la natura et les effets des fiançailles, il est difficile de decider s'ils ont entendu suivre la tradition que Pothier, leur guide ordinaire, expose avec clarté et précision, ou rompre avec elle. Aprés quelques hésitations, la jurisprudence a été définitivement fixeé par um arrêt de la Chambre civile de la Cour de cassation du 30 mai 1.838 (cfe. Lectures II). Elle refuse de reconnaitre la premesse de mariage comme un contrat valable: aucune obligation civile ne nait des fiançailles.

Les tribunaux refusent cependant de se laisser convancre: ils maintienent la mullité de la promesse de mariage. Mais ils ne vont pás jusqu'au bout de leur système, et son ainsi conduits à adopter une position qui manque parfois de logique. Ils estiment que, si les fiançailles ne prevent pás créer d'obligation civile à la charge des fiancés, elles ne son pás pour autant dénuées de tout effet.

Ils admettent que la promesse de mariage fait naitre, à défaut d'une obligation civile, une obligation naturelle. Aussi, lorsque le fiancé qui rompt sa promesse verse une somme d'argent à l'autre fiancé, il ne lui fait pas une donation: il execute son obligation naturelle. Et, lorsqu'il a pris l'engagement de payer, cet engagement, ayant une cause (l'obligacion naturelle), est valuable; il peut donc être constraint à l'exécuter.

$\mathrm{Ne}$ voulant pas considerer les fiançailles comme un contrat valable, les tribunaux ne pouvaint pas, en cas de rupture, engager la responsabilité contractuelle de l'un des fiancés à l'égard de l'autre, ils se sont alors tournés vers la responsabilité extracontractuelle: ils ont décidé que le fiancé qui rompt sa promesse peut, en virtu de l'article 1382 C. Civ., engager sa responsabilité délictuelle ou quasi délictuelle. En effet, il a pu commettre une faute soit en promettant mariage à la légère, soit en rompant sans motif sérieux, par méchanceté ou par caprice. Une telle attitude fautive est susceptible de causer un préjudice material et moral, par suite d'obliger à réparation. Ce n'est pas la rupture, en elle-meme, qui constitue une faute, puisque le fiancé n'est pás tennu de se marier; ce sont les circonstances accompagnant cette rupture qui peuvent être fautives. ${ }^{36}$

Mazeaud finalmente, anunciando uma larga tradição histórica dos esponsais, assim se manifesta:

En usage de tous les milieux, fortes d'une longue tradition historique, les fiançailles n'ont pas été rayées du droit positif, par cela seul que les rédacteurs du Code Civil ont omis

36 MAZEAUD et MAZEAUD. Leçons de Droit Civil. Tome Premier, quatri 'me Édition, Deuxième volume, n. 725, p. 65-7; n. 728, p. 70, Édition Montchestien, Paris, 1963. 
de les mentionner. Plusiers codes étrangers étudient leurs effets. Les rédacteurs de l'avant-projet de code civil y ont consacré les articles 267 et 268.

Ces derniers textes retiennent non seulement la responsabilite du fiancé qui rompt abusivement, mais s'il est mineur, la responsabilité des personnes qui, ayant autorité sur lui, l'ont incité a rompre. D'autre part, le fiancé qui, par sa conduite, donne a l'autre de justes motifs de rompre est tenu de réparer le préjudice quéil cause; disposition heureuse: elle empêche que l'un des fiancés, connaissant la responsabilité quéil encourrait en cas de rupture, évite d'en prendre l'initiative en adoptant une attitude telle que l'autre fiancé se trouverait contraint de rompre. Le fiancé, responsable de la rupture, doit réparer le préjudice, matériel et moral, qu'il cause non seulement à l'autre fiancé, mais aux père et mére, de celui-ci ou aux personnes qui remplacent les père et mère, $c^{\prime}$ està-dire, selon l'exposé des motifs, les grands-parents oncles ou tantes, parrain, marraine ou amis qui... auraient fait des dispenses en vue de la péparation du mariage. ${ }^{37}$

Relativamente às codificações civis argentinas, uruguaia, chilena e colombiana, integrantes da quarta categoria, segundo a excelente classificação concebida pelo Professor Eduardo de Oliveira Leite, embora declarem que a lei não recebe os esponsais como categoria jurídica e, consequentemente, inadmitem qualquer ação de indenização por danos resultantes do descumprimento dessa relação travada entre noivos, a título de compromisso de matrimônio, mas, assim mesmo, registram algumas referências aos esponsais. ${ }^{38}$

Caso específico é o do Código Civil do Uruguai, que revela expressamente a posição de sua legislação nacional, ao considerar o instituto uma pura e simples relação interna entre pessoas que diz respeito à honra e à consciência de cada um. Eis o que contém nas disposições dos artigos 81 e 82 da codificação civil uruguaia, verbis:

Art. 81. Los esponsales o sea la promessa de matrimonio mutuamente aceptada, es um hecho privado, que la ley somete enteramente al honor y conciencia del individuo y que no produce obligación alguna en el foro externo.

No se puede alegar esta promessa ni para pedir que se efectue el matrimonio ni para demandar indemnizacion de perjuicios.

Art. 82. Tampoco podrá pedirse la multa que por parte de uno de los esposos se hubiese estipulado a favor del outro, para el caso de no cumplierse lo prometido. 
Pero si se hubiese pagado la multa, no podrá pedirse su devolución (Artículos 1.441 y 1.445). ${ }^{39}$

Veja-se que o sistema uruguaio admite que os esponsais podem transformar-se em obrigação natural, pois declaraserirrepetível opagamento realizado espontaneamente pela parte que tiver dado causa à outra, do prejuízo por esta sofrido, em razão do descumprimento da promessa entre ambas realizada, como está registrado na parte final do artigo 82, supratranscrito.

\section{OS ESPONSAIS PERANTE O DIREITO BRASILEIRO}

Para examinar com propriedade as nuances e perspectivas experimentadas pelos esponsais na rotina do direito brasileiro, há que se iniciar tal análise a partir do próprio período de formação das nossas instituições jurídicas. Sabe-se que proclamada a independência do país no ano de 1822, o novo Estado restou inteiramente carente de uma estrutura jurídica para ordenar as suas atividades políticas, legislativas e administrativas. Assim, em 3 de maio de 1823, era nomeada por D. Pedro I uma Assembleia Constituinte e Legislativa para elaborar a Constituição Imperial e as novas leis infraconstitucionais brasileiras. Por absoluta inexistência do tempo necessário para a elaboração do complexo constitucional e legislativo do país, optou a dita Assembleia por promulgar a vigência temporária das Ordenações Filipinas para regerem a vida brasileira, até que a legislação própria fosse editada. Tal veio a ocorrer, na área Civil, até 31 de dezembro de

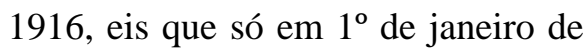
1917 entrou em vigor a nossa primeira codificação civil de $1916 .{ }^{40}$

Pois bem, quando vigente entre nós as Ordenações Filipinas, e ainda no período colonial, a Lei de 6 de outubro de 1784, que introduziu alteração no Código filipino, estabeleceu que o contrato de esponsais deveria ser formalizado mediante escritura pública, lavrada por Tabelião da sede em que se realizasse o ato, firmada pelas partes, seus pais, ou, na falta destes, pelos tutores ou curadores e com a presença de duas testemunhas. Se o tabelionato tivesse sua sede a mais de duas léguas da residência dos contratantes, a promessa poderia ser lavrada por instrumento particular,

39 CÓDIGO CIVIL DE LA REPUBLICA ORIENTAL DEL URUGUAI. Tomo I, Titulo I, p. 111. Montevideo: Edición Fundación de Cultura Universitária, 1999.

40 NORONHA, Carlos Silveira. Sentença Civil-Perfil Histórico-dogmático. n. 9.2, p. 250-1, São Paulo: Edição RT, 1995. 
caso em que era exigida a presença de quatro testemunhas, devendo, ainda, ser a escritura particular reduzida à forma pública. Descumprida essa exigência legal, era o ato considerado inválido.

Sobreveio, entrementes, o Decreto n. 181, de 24 de janeiro de 1980, que extinguiu o casamento religioso, mantendo apenas o civil, omitindo-se, também, de qualquer referência aos esponsais. ${ }^{41}$

No projeto do primeiro Código Civil Brasileiro, da autoria de Clóvis Bevilaqua, havia dois dispositivos acerca da promessa de casamento nos artigos 209 e 210, dispondo o primeiro que:

As promessas de casamento futuro não produzem obrigação legal de contratá-lo, sendo nulas as penas convencionais estabelecidas para o caso rompimento do contrato esponsalício.

A Comissão Especial da Câmara dos Deputados, que examinou o Projeto de Bevilaqua, o relator do Projeto, Anísio de Abreu, reputou inúteis tais disposições, tendo em vista que no contexto da proposta de Clóvis não estavam contemplados os esponsais.

A atual codificação civil brasileira de 2002 continua a não contemplar especificamente os esponsais no âmbito do direito de família. No entanto, não deixa, de certo modo, de fazer referência à doação feita em contemplação de casamento futuro, no campo do direito das obrigações, segundo dispunha o artigo 1.173 da codificação civil de 1916, cuja redação era a seguinte:

A doação feita em contemplação de casamento futuro com certa e determinada pessoa, quer pelos nubentes entre si, quer por terceiros a um deles, a ambos, ou aos filhos que, de futuro, houverem um do outro, não pode ser impugnada por falta de aceitação, e só ficará sem efeito se o casamento não se realizar.

A mesma disposição, com idêntica redação, encontra-se no artigo 546 da codificação atual, de 2002, de modo que a legislação pátria não está a ignorar, ainda que implicitamente, no caso, a existência de um compromisso de matrimônio futuro entre pessoas de sexo oposto.

Mas, em realidade, a doutrina e a jurisprudência nacionais vêm, desde a vigência da codificação civil de 1916, entendendo constituírem os esponsais suporte fático passível de receber juridicidade, no campo do direito das obrigações, toda vez que a promessa

41 CHAVES, Antonio. Quebra de promessa de casamento - devolução dos presentes de noivado. Revista Forense. n. 228, ano 65, p. 61. Rio de Janeiro, 1969. 
de casamento for individualmente descumprida por um dos promitentes e vier a causar prejuízo ao outro.

Assim, é a doutrina de Pontes de Miranda que em tal sentido se manifesta, verbis:

No Brasil, no terreno exclusivo do direito das obrigações, são admissíveis as ações contratuais e as ex delicto. No direito anterior ao Código Civil, já tão pouco usado era o contrato esponsalício que, na Consolidação das Leis Civis, em nota 1 ao artigo 76, Teixeira de Freitas o considerava obsoleto. $\mathrm{O}$ Decreto $\mathrm{n}^{0} 181$, de 24 de janeiro de 1890, nada dispôs a respeito, se bem que não no houvesse extinguido. $\mathrm{O}$ Código Civil aboliu-o do direito de família, onde não há institutos ou categorias jurídicas que não estejam no direito escrito. Isso não quer dizer que houvesse proibido, no direito das obrigações, o contrato esponsalício. Em todo o caso, havemos de entender que as penas convencionais ofendem aos bons costumes, quando concebidas para reforçar as promessas de matrimônio, e que não é lícito obrigar-se à celebração do casamento, ainda que sem a compulsoriedade da cópula carnalis. ${ }^{42}$

Como se constata pela ideia florescente de Pontes de Miranda, supratranscrita, a doutrina e a jurisprudência brasileiras, amparando-se nos históricos precedentes do direito canônico e do direito germânico, não desconhecem nos esponsais o dúplice conteúdo configurado na sponsalia de praesenti e na sponsalia di futuro. Quanto ao primeiro conteúdo abrangido pela sponsalia de praesenti, não cabe a nenhum dos participantes do pré-contrato de promessa de casamento exigir do outro a realização compulsória do matrimônio, porquanto em face da liberdade de escolha do consorte no ato nupcial ser considerado também um direito fundamental da pessoa humana, não é permitido que alguém seja constrangido a casar com outrem contra a sua expressa manifestação de vontade, já por que é o matrimônio um ato solene e de alta valoração para a vida humana. Mas, no que diz com o outro conteúdo e efeitos dos esponsais, a sponsalia de futuro, assim também denominada pelos canonistas, a nossa doutrina e jurisprudência os vêm acolhendo no sentido de conceder reparação dos prejuízos causados pelo descumpridor da promessa, ao outro compromitente, no que se refere aos danos materiais e morais, estes últimos com as devidas cautelas.

Deve ser observado que embora tenha Pontes de Miranda escrito seu tratado sob a vigência do Código Civil

42 PONTES DE MIRANDA. Tratado de Direito Privado. Tomo VII, § 764, n. 5. Rio de Janeiro: Edição Borsoi, 1971, p. 202. 
de 1916, suas ideias refletiam, naquele passo e no transcurso dos tempos, o entendimento majoritário da doutrina e das legislações estrangeiras, inclusive a dos canonistas, que contemplam os esponsais.

Essa posição do festejado autor está, em poucas conotações diversas, confirmada pela doutrina atual, entre tais, a de Washington de Barros Monteiro, a seguir expostas:

Os esponsais são popularmente denominados como noivado e podem ser definidos como a promessa recíproca que um homem e uma mulher fazem de casar, em determinado prazo.

No direito romano era um contrato verbal - sponsio -, que se realizava como o atual noivado. O compromisso de casamento era feito com o consentimento dos pais dos noivos, perante parentes e amigos, oportunidade em que o noivo dava à noiva $o$ anel esponsalício. $\mathrm{O}$ rompimento do noivado dava margem a uma ação de perdas e danos - actio de sponsu. No direito brasileiro pré-codificado, a Lei de 6 de outubro de 1784 conferia expressamente natureza contratual aos esponsais, exigindo-lhes a forma de escritura pública, sendo que seu inadimplemento resolvia-se em perdas e danos.

O noivado era relação de fato, sem efeitos jurídicos imediatos, que ainda hoje tem grande relevância social. Muito embora o noivado seja uma promessa de casamento, seu cumprimento não pode ser exigido, tal como ocorre, por exemplo, na promessa de compra e venda. O noivado não gera obrigação de casar.

O Código Civil não regula os esponsais e a responsabilidade pelo rompimento do noivado. ${ }^{43}$

No entanto, é suficiente a disciplina, constante do art. 186, que estabelece as regras gerais dos atos ilícitos e da responsabilidade civil no artigo 927, que se aplicam a todas as relações civis, para tutelar, segundo a doutrina e jurisprudência nacionais, eventuais dissídios emergentes dos esponsais e reparar os prejuízos, se for o caso.

\section{CONSIDERAÇÕES FINAIS}

Avaliadas todas as particularidades e as minudências circunstanciais que envolvem os esponsais nos sistemas jurídicos examinados, não parece tornar-se tarefa infundada concluir-se que esse instituto, quando acolhido ou simplesmente referido pelas legislações, pode deveras provocar efusivas considerações na esfera do direito das obrigações e notabilizantes efeitos no âmbito do direito de família.

43 BARROS MONTEIRO, Washington - Curso de Direito Civil - Direito de Família. vol. 2, revisada e atualizada por Regina Beatriz Tavares da Silva, 42a . Rio de Janeiro: Edição Forense 2012, p. 117-118. 


\section{REFERÊNCIAS}

ASCARCELLA, Agatina Stefania. Libertá Matrimoniale e Stipulatio Poena - Studia et Documenta Historiae et Iuris v. LXVI, p. 14950. 2000.

BEVILAQUA, Clóvis. Direito de Família. Cap. 2. Recife: Ramiro M. Costa \& Cia., 1896, p. 11-3.

BUZZATTO, Ignazio. Il Problema D'Origine del Processo Extra Ordinem. Bolonha: Casa Editrice Prof. Ricardo Petron, 1965, p. 15-6. ; CABREROS DE ANTA, Marcelino. et al. Código de Derecho Canónico de 1917. Ed. Bilíngue Latin-Espanhol. Madrid: Ed. Biblioteca de Autores Cristianos, 1974, p. 390.

CANNATA, Carlo Alberto. Profilo Istituzionali del Processo Privato Romano, II. Il Processo Formolare. Turim: Giappichelli Editore, 1982.

CHAVES, Antonio. Quebra de Promessa de Casamento - Devolução dos presentes de noiva. Revista Forense. n. 228, ano 65, p. 61, Rio de Janeiro.

Lições de Direito Civil. Direito de Família. v.I. São Paulo: Editora Revista dos Tribunais, 1974.

CÓDIGOCIVILDE LAREPÚBLICA ORIENTAL DEL URUGUAI, Tomo I, Título I, p. 111, Edición Fundación de Cultura Universitaria, Montevideo, 1999.
DAL COL, Helder Martinez. União estável e contrato de namoro no Código Civil de 2002. Disponível em: <http://jus.com. br/artigo7100>.

DE PLÁCIDO E SILVA. Vocabulário Jurídico. 15. ed. Rio de Janeiro: Forense, p. 318.

DIAS, Maria Berenice. Manual de Direito das Famílias. São Paulo: Edição Revista dos Tribunais, 2006, p. 66.

HORTAL, Jesus Pe. Código de Direito Canônico de 1983. Traduzido para o português e comentado. p. 469. São Paulo: Edições Loyola, 1987.

JOSSERAND, Louis. Cours de Droit Civil, v.I, n. 740, Paris: L.G.D.J., 1955.

KIPP, Theodor. In: ENNECERUS, Ludwig; WOLFF, Martin. Tratado de Direito Civil. Cuarto Tomo: Derecho de Família. p. 25-6; 312; 40-7. 2. ed. Trad. espanhola de Blas Pérez Gonzáles y José Castán Tobeñas. Bacelona: Boch Casa Editorial S.A., 1953.

LEITE, Eduardo de Oliveira. Rompimento da Promessa de Casamento - Reparação dos Danos Material e Moral. Revista Ajuris. n. 51, ano XVIII, março de 1991, p. 70.

LOBO, Paulo. Direito Civil - Famílias. 2. ed. São Paulo: Saraiva, 2009, p. 156. 
MAZEAUD et MAZEAUD. Leçons de Droit Civil. Tome Premier, Quatrième Édition, Deuxième Volume, n. 725, p. 65-7; n. 728, p. 70. Paris: Éditions Monchrestin, 1963. MOREIRA ALVES. Direito romano, II. 5. ed. Rio de Janeiro: Forense, 1995, p. 335 e 337.

NORONHA, Carlos Silveira. Sentença Civil - Perfil Histórico - Dogmático. Revista dos Tribunais. n. 6.2, 6.3 6.4. p. 11130. São Paulo, 1995.

NOVARA, Giampaolo. La promessa de matrimônio. L.V.P.A. p. 10, Gênova, 1950. Apud CHAVES, Antonio. Quebra da Promessa de Casamento - devolução dos presentes de noivado. Revista Forense. n. 228, p. 59-67, Rio de Janeiro, 1969.
PONTES DE MIRANDA. Tratado de Direito Privado. Tomo VII, § 764, n. 5. Rio de Janeiro: Edição Borsoi, 1971, p. 200-2.

RAVACH, Alex. Diferença entre namoro e união estável - Jus Navegandi, Teresina, ano 16, $\mathrm{n}^{\circ}$ 2768, 29 jan. 2011. Disponível em: http://jus.br/revista/texto/18383. SCIALOJA, Vittorio. Corso di Istituzioni di Diritto Romano. Anônima Romana Editoriale, Roma, 1934, p. 195-6.

VIERO, Ângela Cristina. EsponsaisEvolução (ocaso?) História e Lineamentos Atuais do Instituto no Direito Brasileiro e Comparado, p. 4-5. (Seminário apresentado por esta Doutoranda no encontro de Doutorandos e Mestrandos da UFRGS, no semestre 2011/2). 